\title{
From "Academic Projectitis" to Partnership: Community Perspectives for Authentic Community Engagement in Health Professional Education
}

\author{
Cathy Kline, Wafa Asadian, William Godolphin, Scott Graham, Cheryl Hewitt, \\ and Angela Towle
}

\begin{abstract}
AвSTRACT Health professional education (HPE) has taken a problem-based approach to community service-learning with good intentions to sensitize future health care professionals to community needs and serve the underserved. However, a growing emphasis on social responsibility and accountability has educators rethinking community engagement. Many institutions now seek to improve community participation in educational programs. Likewise, many Canadians are enthusiastic about their health care system and patients, who are "experts by lived experience," value opportunities to "give back" and improve health care by taking an active role in the education of health professionals. We describe a community-based participatory action research project to develop a mechanism for community engagement in HPE at the University of British Columbia (UBC). In-depth interviews and a community dialogue with leaders from 18 community-based organizations working with vulnerable populations revealed the shared common interest of the community and university in the education of health professionals. Patients and community organizations have a range of expertise that can help to prepare health practitioners to work in partnership with patients, communities, and other professionals. Recommendations are presented to enhance the inclusion of community expertise in HPE by changing the way the community and university engage with each other.
\end{abstract}

KEYWORDs community engagement, social responsibility, social accountability, health professional education, community-based participatory action research

Community service-learning (CSL) in health and human services education has lagged behind developments in other disciplines. In health professional programs, it is often narrowly conceptualized, viewed largely from the perspective of the university, and focused on service delivery. This focus on health care delivery fits with the service-orientation of the health professions. The opportunities CSL presents to build competencies that students need, through hands-on experience, are powerful factors that have shaped the development of CSL in health professional education.

In a systematic review of service-learning and community-based medical education, Hunt, Bonham and Jones (2011) found that engagement with community is almost entirely 
conceptualized as service or outreach, whereby students provide clinical care and/or health education to the community, not as a collaborative partnership with the community characterized by reciprocal knowledge exchange. The United States (U.S.) experience has been a model for Canada despite very different health care systems. As in the U.S., CSL in the Canadian context is often about students providing health services to marginalized, vulnerable, or underserviced populations (Dharamsi et al., 2010; Gillis \& Mac Lellan, 2013; Harrison, MacNab, Duffy, \& Benton, 2006; Kabli, Liu, Seifert, \& Arnot, 2013).

Behind many programs is the belief that these settings teach students about health disparities, barriers to health care, and the social determinants of health (Hunt, Bonham, \& Jones, 2011). This problem-based approach holds a deficit view of the community in which fixing problems is the focus of student learning rather than community strengths, expertise, and assets. It places students (who are often privileged) in a position of power that can reinforce stereotypes and sustain power disparities (Mitchell, 2008). These approaches uphold power inequalities that are counter to important shifts in health care practice such as patient-centred care (Montague et al., 2017) and shared decision-making (Légaré, Stacey, \& Forest, 2007).

While interest in critical approaches to CSL and other types of community-engaged learning has been growing among educators, movement beyond server-served relationships has not taken hold in health professional education. Scholars have proposed changes to CSL practice that emphasize relationships and attend to issues of power (Bruce, 2013; Butin, 2015; Steinman, 2011), but sharing power with "Others" outside the university is risky, especially for health professionals who benefit from existing power structures that privilege the academy over the community. A move beyond a focus on health care services would consider engagement more widely and identify the supports required for bidirectional relationships between university and community.

The University of British Columbia (UBC) is the major educator of health professionals for the province. There are 15 health and human service programs: audiology and speech sciences, counselling psychology, dental hygiene, dentistry, dietetics, genetic counselling, kinesiology, medicine, midwifery, nursing, occupational therapy, pharmaceutical sciences, physical therapy, population and public health, and social work. Our project team included health education scholars from Patient \& Community Partnership for Education in UBC Health and community leaders from PeerNetBC and the Social Planning and Research Council of BC. We conducted a community-based participatory action research project to co-develop a mechanism for patient and community engagement in health professional education and make way for diverse community organizations and populations to engage with UBC in ways that are valid for the community.

Trends in health care, such as consumerism, the increased need for chronic care, and more involvement of patients in decision-making, provide powerful reasons to involve patients in education (Towle et al., 2010). In order for students to acquire the knowledge, skills, and attitudes to put patient-centred care into practice, patients and their families must become a core part of the education of future health professionals. This idea is intrinsically attractive to communities. However, most patient and community involvement in health professional 
education at UBC, as elsewhere, is small-scale, episodic, and largely dependent upon the efforts of individual faculty members to make it happen. Guest speakers, standardized patients (healthy individuals who are trained to simulate real patients in a realistic and reliable manner), and CSL occur in most programs. There are few examples of involvement in student assessment, curriculum development or institutional decision-making, and coordinated involvement across the continuum of education does not exist. Some programs, such as the four-year Entry-toPractice Doctor of Pharmacy degree (PharmD) program, have dedicated CSL courses. These usually occur during pre-clinical training to give students community experiences prior to clinical or practicum placements. Our study aimed to find ways to move beyond approaches to CSL and community engagement in which the community is simply a venue for student learning. It sought to expand the role of community in health professional education and make way for public input in university programs.

The benefits of active involvement of patients and community members in educational programs include improved student learning and patients' satisfaction in contributing to the education of future health professionals (Towle et al., 2010). But most involvement is episodic, occurring when people from various groups are invited into the classroom to talk about their experiences. Towle et al. (2010) suggest that "if education is to promote partnerships with patients as the basis for health care, we must move from isolated initiatives to coordinated and sustained programmes that develop patient involvement curricula and authentic partnerships at an institutional level" (p. 71). However, research has identified major institutional barriers to authentic involvement of community members in higher education, including power imbalances, stigma, differences in faculty and community members' theories of learning, and the dominance of biomedical knowledge over patients' lived experience (Bacon 2002; Basset, Campbell, \& Anderson, 2006; Caron-Flinterman, Broerse, \& Bunders, 2005; Towle \& Godolphin, 2011). These barriers marginalize community voices in community-university collaborations.

Despite such barriers, schools training students in the health and human service professions are preparing students for a special relationship with the community, that of safeguarding health and well-being (Quinn, Gamble, \& Denham, 2001), and many institutions now recognize their responsibility to improve engagement with the communities they serve. This is particularly significant in medicine since the World Health Organization defined the social accountability of medical schools as "the obligation to direct their education, research and service activities towards addressing the priority health concerns of the community, region, and/or nation they have a mandate to serve. The priority health concerns are to be identified jointly by governments, health care organizations, health professionals and the public" (Boelen \& Heck, 1995, p. 3). The Association of Faculties of Medicine of Canada (2010) provided leadership at a national level in this regard by setting out recommendations for the Future of Medical Education in Canada that clearly position social responsibility and accountability as foundational to medical practice and education. The vision states that community participation is critical to achieve social accountability.

Through a community-based participatory action research project, we set out to 
develop a model for community participation in health professional education that would lead to communities' sustained influence on and engagement with the university (i.e., the institutionalization of community engagement). Our project envisions reciprocal sharing of resources between the university and the community, each having different assets and social capital. Our strategy involved professionals, educators, community organizations, and endusers of the health system in a process to explore innovative approaches to improving the knowledge, skills, and attitudes of health professionals who work with vulnerable people. This paper summarizes the process and outcomes of this project, which looked to develop: 1) a mechanism for mutually beneficial engagement between communities and the university; and 2) a sustainable educational model for community involvement in health professional education. The research should lead to diverse end-users of the health care system having a mechanism and the power to have sustained influence on the education of health professionals.

\section{Methods}

\section{Conceptual framework}

We used a "knowledge interaction" approach (Davies, Nutley, \& Walter, 2008) to influence educational policy and practice based on a facilitated two-way exchange of knowledge between multiple stakeholders with diverse sources of knowledge, particularly the university faculty and community. The project engaged both university and community (i.e., patients and civil society organizations) as co-producers and users of knowledge. It is predicated on an understanding of using research that is "interactive, iterative and contextual... [and that] emphasizes social, dialogical and interpretive ways of knowing in an ongoing creative and unfolding process" (Davies, Nutley, \& Walter, 2008, p. 190). We utilized Community-Based Participatory Research (CBPR) methodology, a collaborative approach to research that equitably involves all partners in the research process. CBPR recognizes the unique strengths that everyone brings, with the aim of combining knowledge and action for social change to improve community health and reduce health disparities (Minkler \& Wallerstein, 2008). A core project team of university and community members led the project in consultation with a Research Advisory Committee (RAC) of representatives from community organizations and the university. Guided by CBPR principles, the project utilized a mixture of established research methods for data collection and analysis. Ethics approval was obtained from the university research ethics board.

Key informant interviews and a group dialogue (Israel, Eng, Schultz, \& Parker, 2005) with leaders of community-based organizations generated the data. Research is often the domain of the academy and research agendas are usually driven by academic priorities. Community input is most often gathered after the fact, if at all. Thus, we began our investigation in the community. The study was guided by five over-arching questions: 1) What are the characteristics of a partnership between university and community for the purpose of health professional education? 2) What does the process of bilateral engagement and dialogue look like? 3) How can barriers to authentic participation of vulnerable populations be addressed? 4) What kind of educational models can facilitate on-going and authentic involvement of patients/citizens 
in health professional education? and 5) What are the benefits to the community?

\section{Participants}

Informant selection and recruitment began with the key informant interviews. The core project team developed a list of approximately 60 contacts within community-based organizations known to work with vulnerable/marginalized populations in British Columbia. From this reference group, we created a short-list of 30 contacts known to be involved in education and thought to be potential educational partners who could contribute to health professional education. In consultation with the RAC, we further refined this list to identify key informants who are well-connected in the community.

We emailed an invitation letter to 20 key informants (e.g., Executive Directors, CEOs) of shortlisted organizations that serve vulnerable populations including Aboriginal people, immigrants, refugees, women, seniors, youth and families, people with chronic disease/ disabilities, mental health conditions, HIV/AIDS, and Alzheimer's. We invited them to take part in an interview to explore their ideas about how to involve community organizations and individual patients/clients in the education of health professionals at UBC. Seventeen key informants were interviewed.

Following the interviews, informants, community representatives, and members of the RAC gathered in a dialogue to check and confirm findings from the interviews, get input on process through identification of action items and next steps, and build connections and collective commitment to take the work forward. We invited all those who participated in the key informant interviews to the dialogue, as well as representatives of organizations who had been contacted for interviews but were either unable to take part or did not respond to the initial invitation. Key informants were also invited to bring a colleague from their organization. Twenty-six participants, including members of the RAC and project team, attended the dialogue. In total, 35 individuals took part in the interviews and/or community dialogue. Participants included representatives from 18 community organizations, the RAC, the core project team, and the interviewers. Community organizations represented the following sectors: chronic disease (3); disabilities (3); immigrants (3); mental health (2); HIV/AIDS (2); sexual health (2); seniors (1); non-specific (2). Some of the organizations are local or provincial chapters of well-known national organizations.

\section{Key informant interviews}

Interview design. The project team developed the interview protocol and revised it after consultation with the RAC and pilot testing. Questions led participants from describing concrete aspects of their work (e.g., their organization's educational activities, philosophy, etc.) to their ideas about how health professionals should behave differently. The questions concluded with more abstract thinking about processes and structures that would be required to involve vulnerable people in health professional education at UBC. We e-mailed in advance an information sheet outlining a spectrum of involvement containing examples from the literature of patient/ community roles in health professional education in six categories (Appendix 1). During 
the interviews, this spectrum helped participants identify aspects of patient involvement in education that were of most interest or relevance to them. Subsequent questioning focused on the supports, barriers, processes, and structures required for authentic participation of patients in health professional education. Interviews were conducted by a member of the core team and two individuals with prior interview experience and/or experience working in a community-based organization serving vulnerable populations. Interviewers received two half-day training sessions to familiarize themselves with the interview protocol and techniques. The training included a video-taped practice interview with a volunteer from a communitybased organization.

Interview analysis. Interviews were audio-recorded and transcribed verbatim. Transcripts were reviewed to identify key themes for each topic area covered in the interviews. Selections of narrative from the transcripts were organized by themes under each of the following topic areas addressed in the interviews: 1) What educational activities are being done/have been done that can be built upon? 2) How should health professionals behave differently? 3) What kinds of involvement are of most interest/relevance? 4) What needs to happen to support community involvement? 5) What community processes and structures are needed? 6) What university processes/structures are needed? 7) What can patients/citizens teach? 8) What are the benefits to community? The summary report organized key findings by interview topic area, each including a high-level summary of the data and an inventory of relevant narrative organized thematically.

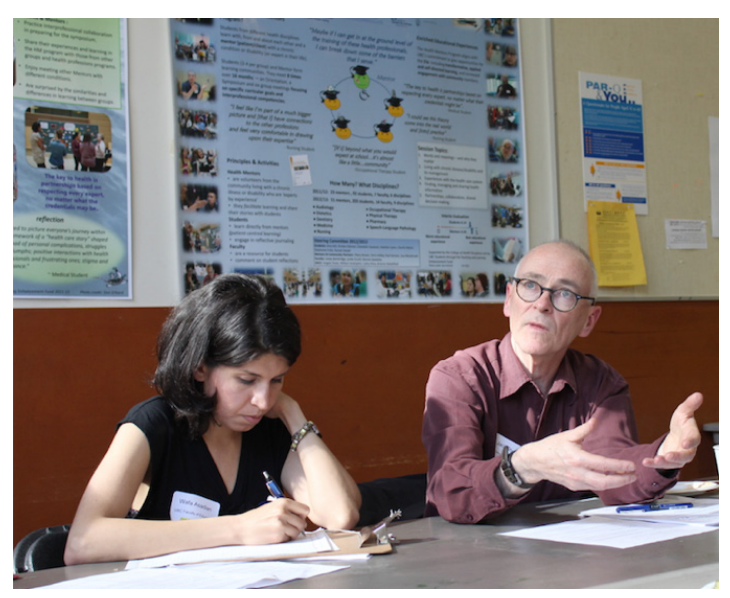

Photo by: UBC Patient \& Community Partnership for Education

\section{Community dialogue}

Dialogue process. We pre-circulated a draft summary report of the key informant interviews to participants. The dialogue session began with a presentation of the overall project and interview findings. Participants then self-selected into one of three dialogue tables, each focused on a cluster of the key findings from the summary report. Each dialogue table was asked to complete these tasks: 1) review the subset of key findings and rank in order of importance; 2) identify issues or disagreements; and 3) suggest action items for each key finding and identify two or three specific next steps to act on the key findings in the subset. The dialogue concluded with presentations of the key points from each group and a summary of next steps, including some modifications to the project process based on ideas emerging from the dialogue tables. 
Data synthesis. The core team took detailed notes at each dialogue table and the plenary and compiled those into a single document. Two team members extracted key ideas and implications, which were then reviewed and agreed to by the whole team before being compiled into a dialogue report. We sent the draft report to all those who attended with a request for feedback, resulting in small editorial changes.

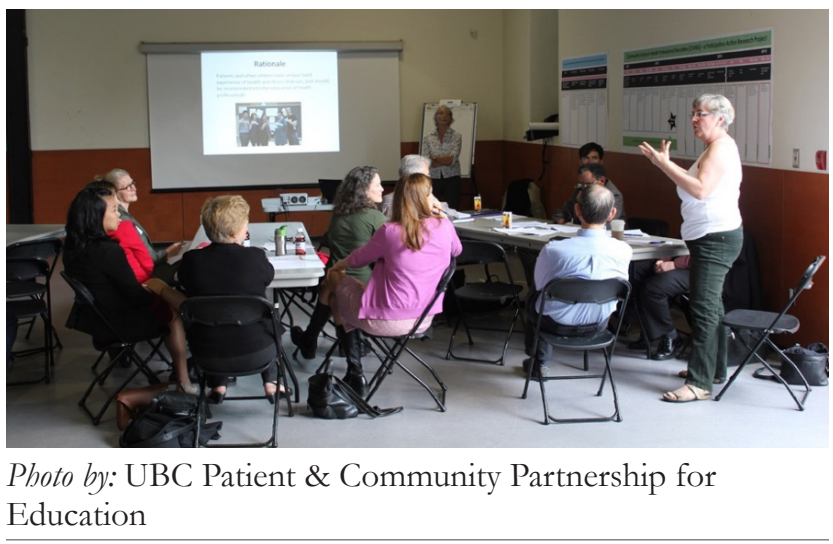

\section{Results}

We present here a synthesis of the results from the interviews and dialogue. The key findings fell into three clusters: involvement in the education of students; supporting community educators; and engagement between community organizations and the university (See Appendix 2).

\section{Involvement in the education of students}

Discussions of how health professionals should behave differently (and therefore what changes were needed in their education) focused on the need for health professionals to work in partnership with patients and other health professionals. Informants indicated that partnership requires health professionals to recognize the expertise of others, understand patients' lived experiences, take a holistic approach, be non-judgmental, and be more sensitive to cultural and language barriers. Dialogue participants identified the following concept as the ultimate long-term goal of the project: if involving people from the community in education works, then health professionals will be better at working in partnership.

Informants thought that the communities they serve have a lot to offer students, including teaching about patients' lived experience, stigma, advocacy, communication skills, and cultural knowledge. They suggested documentation of this expertise would be a good method for the community and university to jointly identify opportunities to work together to address students' educational needs.

Informants identified examples of ways in which members of their organization could participate in education along the spectrum of involvement (see Appendix 1). Creation of learning materials and sharing personal experiences were identified as the most obvious and easiest ways in which community could be involved initially. Dialogue participants raised concerns about differences in language (between university and community), the need for the university to recognize different educational activities as valid (such as experiential learning), and the university's habit of asking the community for input or participation after the fact.

Learning opportunities involving vulnerable citizens will be very different from the ways of learning familiar to students. Informants stressed that students need to be prepared to "get 
their hands dirty" and understand the need to respect the opportunity to learn from vulnerable citizens as a privilege not to be taken lightly. Some organizations recounted bad experiences with students who did not see the value in some of the work they were asked to do in a community placement. There was some disagreement at the dialogue about whose job it is to prepare students. Most saw preparation as a university responsibility but they also saw a need to involve community.

\section{Supporting community educators}

In the ranking exercise, dialogue participants identified recognizing and honouring patient expertise as the most important finding in this cluster. Sharing one's lived experience can be emotionally taxing and risky because of the uncertainty about how one's story will be received. If people do not feel valued and their contributions are not recognized and rewarded appropriately, they may feel exploited and/or disengage from the process. Thus, both emotional and monetary compensation are important. In our study budget, we built in consultancy fees to pay our community partners and honoraria to hire community interviewers and pay participants. But securing long-term, sustainable funding to compensate patients for their expertise and contributions to health professional education will no doubt be a challenge. For many community-based organizations, education is part of their mandate and health professional education could be included as part of their operations. Of course, there are limitations to the community's ability to pay, and larger organizations may have more capacity than smaller ones. Sharing responsibility and accountability for health professional education requires a reciprocal sharing of resources between the university and community, recognizing that each will have different assets and capital to contribute to the partnership. Systems of acknowledgement and recognition need to be developed that are commensurate with community educator contributions and guided by principles co-created by community and university.

Informants were united in the view that students would have to come to the community

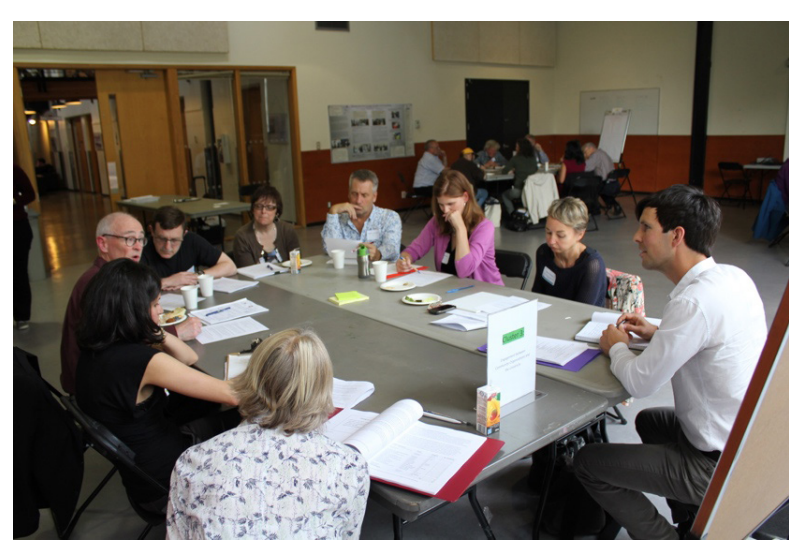

Photo by: UBC Patient \& Community Partnership for Education in order to appreciate and learn from people who are marginalized. Although many liked the idea of creating opportunities for their members to come to campus, the university seems inaccessible to people who are most vulnerable and marginalized. The most authentic learning about people's lived experiences would take place in the community. Dialogue participants identified a number of factors to address in order to include vulnerable populations from the community, including appropriate meeting spaces,

Engaged Scholar Journal: Community-Engaged Research, Teaching, and Learning 
meeting times, and important etiquettes.

Vulnerable people and those with chronic conditions or disabilities have significant challenges that will compete with their ability to participate in education. Educators need to create conditions to facilitate these people's involvement when they are ready and able, and account for times when they will be unable to take part. The issues of power, confidence, self-efficacy, varying levels of literacy, level of personal comfort, and individual circumstances also need to be addressed. Dialogue participants identified the need for guiding principles, including understanding of the intersection of vulnerabilities and identities and the importance of a strengths-based approach. They also thought that the university should encourage opportunities for students to explore their own vulnerabilities rather than seeing themselves as "fix it" persons. The group noted that there are also vulnerable populations on campus.

Many individuals will need training and support to acquire the skills and confidence to be effective teachers. For example, training should be offered to vulnerable people about how to tell their stories in ways that are helpful to students. Informants thought that few people would initially have the skills and confidence for involvement in assessing students, curriculum development, or decision-making at the institutional level. The gradual entry of such people into the education process could begin with preparation in the community by their community organizations, leading to involvement beyond curriculum delivery. Some types of involvement would require mentorship from the university.

\section{Engagement between community organizations and the university}

The findings in this cluster were all interlinked according to dialogue participants. Through the ranking exercise at the dialogue, the idea of building reciprocal, long-term, respectful relationships with people and organizations emerged as most important. Long-term buy-in from the community and effecting long-term change requires deep commitment to building ongoing partnerships. In contrast to this approach, one informant characterized the current revolving door of students and university projects that flow in and out of her organization as "academic projectitis." While they see the obligations as important, these relationships are taxing for community organizations.

On-the-ground staff members within community organizations are best situated to recruit and support patient and community educators. They have established trusting relationships in the community and they know their members' skills and abilities, special needs, individual circumstances, readiness to participate, etc. A dedicated staff member within the community organization would also help to create and sustain institutional commitment within the organization.

Informants identified the need for a mechanism for efficient information sharing, reporting, and problem-solving between community and university. Such a mechanism requires liaisons from both groups who can work effectively to resolve issues in a timely manner. The dialogue group also confirmed the need for a single agency in the community ("a vessel or container 
that keeps all the groups together"). ${ }^{1}$ Each organization has different assets and needs, so they need to create unity of purpose. Dialogue participants warned that we must not underestimate the amount of time this will take, given the complexity of the issues.

Community participants saw a community-university partnership offering both shortand long-term benefits for the community. In the short term, it would validate the work of community organizations, be seen favorably by funders, and have direct benefits for participating community members (e.g., personal growth, empowerment). In the long term, key informants envisioned better health care provided by health professionals who are more responsive to community needs. Although organizations see the benefit of collaborating with the university, practical considerations, such as funding and time, need to be addressed. Dialogue participants noted how under-funded and under-resourced community organizations are when it comes to planning a large-scale educational activity.

Dialogue participants knew how community organizations work and how to get things done (e.g., what information would be needed by Boards and for memoranda of understanding (MOUs)). They identified the need for community and university partners to create a common vision, perhaps through linking community involvement in health professional education to trends like involving patients as partners in health care. Participants believed that the foundations for MOUs would require a set of facilitated conversations through which some of the big issues such as language, power differences, and reciprocity could be addressed.

\section{Discussion}

Our study reveals a number of promising ideas to enhance university-community engagement for student learning and health equity. Although our study was done in the context of health professional education, many of the issues and solutions have general applicability to higher education in Canada. The study identifies two fundamental barriers to embedding community expertise in education: 1) getting the community and university to work together as peers; and 2) building long-term, reciprocal partnerships between the university and community. Below, we provide a list of best practices for addressing these barriers. Although similar lists have been generated by previous research, in the context of community service-learning in the health professions, our community participants confirm that they are far from being established practice.

\section{The community and university should work together as peers}

The concept of patient involvement in the education of health professionals, flowing from a partnership between community and university, was a new idea for most of the community organizations in this study. Their previous experience was reactive, responding to requests from the university. Indeed, power imbalances between university and community organizations permeated many of the conversations. The university was seen as "all knowing," the leader in the relationship, and the community as reactive, following the university's lead. This is

\footnotetext{
${ }^{1}$ See Briggs (this issue) for more on the idea of hub organizations.
} 
consistent with Bacon's (2002) finding that community partners tend to view expert knowledge as residing in the university. Through our study, the following ideas emerged that could help overcome the long-standing notion that institutions of higher education have the answers and solutions for communities, who are seen as passive beneficiaries of university expertise.

\section{Document community expertise}

Community members have a variety of expertise to share with health professionals. A good starting place for partnership would be to identify, through an asset-based approach, areas that are of mutual interest but difficult to teach in academic or clinical settings. For example, advocacy, communication skills, and cultural and experiential knowledge were identified as relevant areas of community expertise. These topics are not easily taught in the same ways as biomedical knowledge, and sharing this expertise offers a way to put power in the hands of the community.

\section{Develop the role of community as partners in education}

Authentic community engagement at an institutional level will require a shift to engaging with the community as partners in education. Co-creation of educational materials and co-teaching could lead to community involvement in other educational processes such as assessment, curriculum development, and institutional decision-making. Worall (2007) found that community-based organizations' perceptions of themselves as educational partners developed over time. This suggests an approach whereby community partners incrementally develop their role as educators. Engaging community in the design and delivery of orientation activities for community-based learning is a logical way to begin to partner with community members in curriculum development and decision-making.

\section{Learning activities that involve vulnerable citizens should be in the community}

Due to the inherent power imbalance between the university and vulnerable citizens, learning from these community members must take place in the community. Guiding principles for engagement must emphasize students' roles as "learners," not "fixers." Different types of meeting spaces are important not just as locations for meeting people from the community, but as learning environments different from the university classroom or clinical settings.

\section{Develop a unified entity in the community}

To develop the idea of community-university collaboration, coalition, or networking, community needs to have a collective voice to engage with the university. Participants recommended staff liaisons in community organizations to broker relationships with the university and create institutional commitment in the organization. Weerts and Sandman (2010) identified boundary-spanning roles played by university staff and faculty in communityuniversity engagement at research-intensive universities. Boundary-spanning involves building bridges from campus to community and relies on key players whose roles are to work inside and outside the university to help campuses engage with communities. Our findings suggest a 
need for designated community equivalents to university boundary-spanners. This community organizing work will help shift power and make way for the community and university to work together as peers. We have made progress to this end by supporting the development of Patients in Education, an independent organization in the community whose members are representatives of community organizations and individuals who wish to advance patient/ community involvement in the education of health professionals.

\section{Build long-term, reciprocal relationships}

The central theme of long-term, reciprocal relationships contrasts with how community organizations in this study have been engaged by higher learning institutions. The metaphor of "academic projectitis" emerged here. Informants characterized their prior involvement with the university as excluding and lacking partnership values, a finding documented in the literature (Hunt, Bonham, \& Jones, 2011). Language, power differences, and reciprocal relationships need to be addressed in order to move towards a shared vision and the eventual co-creation of MOUs, important foundations for institutionalized community involvement. Dostilio, Brackmann, Edwards, Harrison, Kliewer, \& Clayton (2012) call this approach generativity-oriented reciprocity, wherein participants develop identities as co-creators and generate new ways of knowing and being that allow for new ways of engaging. Through our research, the following practical ideas emerged that could help to build more equitable community-university partnerships and expand community engagement in health professional education.

\section{Develop a shared vision focused on student learning}

Many community organizations' missions, including many of those in the present study, seek to educate the next generation of professionals, citizens, board members, policy makers, and funders. Studies of long-standing CSL partnerships have found that community organizations see a shared responsibility to shape future professionals and will invest their own resources in student learning (Gelmon, Holland, Seifer, Shinnamon, \& Connors, 1998). ${ }^{2}$ Advancing this shared mission promises more equitable, transformative (for students, community, and the university), and mutually beneficial community-university partnerships.

\section{Address language and terminology barriers}

Community organizations may be uncomfortable with words that are used commonly in health professional education. For example, "patient" can be a major trigger for heated debate, but without leading to agreement on an alternative word based on shared understanding. The term "patient" is particularly fraught because it reflects power disparities inherent in the doctor-patient relationship. To overcome these barriers, community and university must explicitly acknowledge disparities in power and privilege and focus on their common interests in educating students. Community partners elsewhere have recommended frank discussions

\footnotetext{
${ }^{2}$ See also Hitchings, Johnson, and Tu'Inukuafe, this issue.
} 
between university and community partners about racial, ethnic, and economic inequalities and their causes as a requirement for establishing good community-university partnerships (Leiderman, Furco, Zapf, \& Goss, 2007). These discussions, especially about language, need to be frequently revisited.

\section{Establish mechanisms for two-way communication}

Partnerships require ongoing dialogue and consistent attention and support. For the informants, communication problems were at the heart of their previous experiences with communityuniversity partnerships. Informants also expressed the need for community organizations to be informed about outcomes. Poor communication about students' learning objectives and a need for greater faculty involvement in the relationship have been identified by community partners in other studies (Gelmon, Holland, Seifer, Shinnamon, \& Connors, 1998; Sandy \& Holland, 2006; Vernon \& Ward, 1999). Mechanisms for two-way communication are critical; community organizations want to know whether or not their efforts make a difference to students.

\section{Recognize and honour patient and community expertise}

Mechanisms to acknowledge and recognize community expertise must be put in place-for example, a collaboratively developed framework with guiding principles (possibly through a joint community-university working group). A range of options within those mechanisms is necessary to ensure broad participation from the community. Communities should be involved in creating guiding principles that take into account the type of participation and population.

\section{Limitations}

The findings are based on the views of representatives of 18 community-based organizations in the Metro Vancouver area. Although some of the organizations are local branches of national organizations, we do not know if the views are generalizable to organizations elsewhere. We were unsuccessful in engaging Indigenous groups, and this is an important gap (but see Bain, this issue, for an example of Indigenous community-university engagement). The next phase of the project is an equivalent study with key stakeholders in the university.

\section{Conclusions}

Our study of how individuals and organizations could be more involved in health professional education, from a community point of view, supports a number of promising directions for community-university engagement that go beyond outreach and service and could begin to address some of the limitations of episodic involvement in curriculum delivery and one-off CSL projects. Many community organizations share a common interest in student education. Communities have a great deal of expertise to share with students and the university. By working together as peers and building long-term reciprocal relationships, people from the community and the university can be co-teachers and partners in education. Re-orienting CSL practice in health professional education to focus not only on the expertise that the university 
can bring to the community but also the expertise the community can share with the university will make for more equitable partnerships that can be more transformative and begin to speak truth to power. Deeper, more systemic involvement of patients and community in health professional education should lead to health professionals who are better able to work in partnership to meet community needs. Community-university partnerships at an institutional level will help universities and health professional schools be more socially responsive and accountable to the communities they serve.

\section{Acknowledgments}

This research was funded by a grant from the Vancouver Foundation. We gratefully acknowledge Research Advisory Committee members Michael Clague, Jane Dyson, Louise Nasmith, Eyob Naizghi, and Jennifer Vadeboncoeur for their assistance with research design and community interviewers Nusha Elliot and R. Paul Kerston for their assistance with data collection.

\section{About the Authors}

Wafa Asadian is a PhD candidate in the UBC Faculty of Education. Her interest and experiences include research and evaluation in social and educational programs.

William Godolphin has been a teacher and researcher for many years, with projects and publications ranging across lipoproteins, breast cancer, toxicology, automation/robotics and medical education. He is Professor Emeritus in the Department of Pathology \& Laboratory Medicine and Co-director of Patient \& Community Partnership for Education, Office of UBC Health.

Scott Graham is the Associate Executive Director and Manager of Research, Planning and Consulting for the Social Planning and Research Council of British Columbia. Scott specializes in applied qualitative and quantitative research, human development service planning, policy development, capacity building, evaluation and knowledge translation.

Cheryl Hewitt worked with PeerNetBC until her recent semi-retirement. PeerNetBC strives to build strength in community through peer support, which includes assisting health professionals to appreciate the value of peer support in the continuum of care. Cheryl is a community activist who advocates for healthy, inclusive and equitable communities. 
Cathy Kline (corresponding author) is the Research Coordinator for Patient \& Community Partnership for Education in the Office of UBC Health, University of British Columbia. She manages multiple research and development initiatives that aim to improve patient/client involvement in health professional education and health care decision-making. Email: cckline@mail.ubc.ca

Angela Towle is Co-Director of Patient \& Community Partnership for Education in the Office of UBC Health. She is associate professor in the Department of Medicine and senior scholar in the Centre for Health Education Scholarship in the Faculty of Medicine, and Academic Director of the UBC Learning Exchange.

\section{References}

Bacon, N. (2002). Differences in faculty and community partners' theories of learning. Michigan Journal of Community Service Learning, 9(1), 34-44.

Basset, T., Campbell, P., \& Anderson, J. (2006). Service user/survivor involvement in mental health training and education: Overcoming the barriers. Social Work Education, 25, 393-402.

Boelen, C., \& Heck, J. (1995). Defining and measuring the social accountability of medical schools. Geneva, Switzerland: Division of Development of Human Resources for Health, World Health Organization.

Bruce, J. (2013). Service learning as a pedagogy of interruption. International Journal of Development Education and Global Learning, 5(1), 33-47.

Butin, D. (2015). Dreaming of justice: Critical service-learning and the need to wake up. Theory Into Practice, 54, 5-10.

Caron-Flinterman, J. F., Broerse, J. W., \& Bunders, J. G. (2005). The experiential knowledge of patients: a new resource for biomedical research? Social Science \& Medicine, 60, 2575-2584.

Davies, H., Nutley, S., \& Walter, I. (2008). Why "knowledge transfer" is misconceived for applied social research. Journal of Health Services \& Research Policy, 13, 188-190.

Dharamsi, S., Espinoza, N., Cramer, C., Amin, M., Bainbridge, L., \& Poole, G. (2010). Nurturing social responsibility through community service-learning: Lessons learned from a pilot project. Medical Teacher, 32(11), 905-911.

Dostilio, L., Brackmann, S., Edwards, K., Harrison, B., Kliewer, B., \& Clayton, P. (2012). Reciprocity: Saying what we mean and meaning what we say. Michigan Journal of Community Service Learning, 19(1), 17-32.

Gelmon, S. B., Holland, B. A., Seifer, S. D., Shinnamon, A., \& Connors, K. (1998). Communityuniversity partnerships for mutual learning. Michigan Journal of Community Service Learning, 5(1), 97-107.

Gilles, A., \& Mac Lellan, M. (2013). Critical service learning in community health nursing: Enhancing access to cardiac health screening. International Journal of Nursing Education Scholarship, 10(1), $1-9$. 
Harrison, R., MacNab, A., Duffy, D., \& Benton, D. (2006). Brighter smiles: Service learning, interprofessional collaboration and health promotion in a First Nations community. Canadian Journal of Public Health, 97(3), 237-240.

Hunt, B., Bonham, C., \& Jones, L. (2011). Understanding the goals of service learning and community-based medical education: A systematic review. Academic Medicine, 86(2), 246-251.

Israel, B. A., Eng, E., Schulz, A. J., \& Parker, E. A. (Eds.). (2005). Methods in community-based participatory research for health. San Francisco, CA: Jossey-Bass.

Kabli, N., Liu, B., Seifert, T., \& Arnot, M. (2013). Effects of academic service learning in drug misuse and addiction on students' learning preferences and attitudes toward harm reduction. American Journal of Pharmaceutical Education, 77(3). 1-9.

Légaré, F., Stacey, D., \& Forest, P.G. (2007). Shared decision making in Canada: Update, challenges and where next! German Journal for Quality in Health Care, 101(4), 213-221.

Leiderman, S., Furco, A., Zapf, J., \& Goss, M. (2003). Building partnerships with college campuses: Community perspectives. Washington, DC: The Council of Independent Colleges.

Minkler, M., \& Wallerstein, N. (Eds.). (2008) Community-based participatory research for health: from process to outcomes. San Francisco, CA: Jossey-Bass.

Mitchell, T. (2008). Traditional vs. critical service-learning: Engaging in the literature to differentiate two models. Michigan Journal of Community Service Learning, 14(2), 50-65.

Montague, T., Gogovor, A., Aylen, J., Ashley, L., Ahmed, S., Martin, L., Cochrane, B., Adams, O., Nemis-White, J. (2017). Patient-centred care in Canada: Key components and the path forward. Healthcare Quarterly 20(1), 50-56.

Quinn, S. Gamble, D, \& Denham, A. (2001). Ethics and community-based education: Balancing respect for the community with professional preparation. Family \& Community Health, 23(4), $9-23$.

Sandy, M., \& Holland, B. A. (2006). Different worlds on common ground: Community partner perspectives on campus-community partnerships. Michigan Journal of Community Service Learning, 13(1), 30-43.

Steinman, E. (2011). "Making space": Lessons from collaborations with tribal nations. Michigan Journal of Community Service Learning, 18(1), 5-18.

The Association of Faculties of Medicine in Canada. (2010). The future of medical education in Canada: A collective vision for MD education. Ottawa, ON: The Association.

Towle, A., Bainbridge, L., Godolphin, W., Katz, A., Kline, C., Lown, B., Madularu, I., Solomon, P., Thistlethwaite, J. (2010). Active patient involvement in the education of health professionals. Medical Education, 44, 64-74.

Towle A., \& Godolphin W. (2011) A meeting of experts. The emerging roles of non-professionals in the education of health professionals. Teaching in Higher Education, 16, 495-504.

Vernon, A., \& Ward, K. (1999). Campus and community partnerships: Assessing impact and strengthening connections. Michigan Journal of Community Service Learning, 6(1), 30-37.

Weerts, D., \& Sandmann, L. (2010). Community engagement and boundary-spanning roles at research universities. The Journal of Higher Education, 81(6), 702-727.

Worrall, L. (2007). Asking the community: A case study of community partners perspectives. Michigan Journal of Community Service Learning, 14(1), 5-17. 


\section{Appendix 1: Spectrum of Involvement}

1. Patients involved in creating learning materials used by faculty (paper-based or electronic case or scenario; course materials; videos). Examples: real patient problems as basis for casebased learning; virtual patient cases (may involve video of patient); use of patient narratives.

2. Standardized or volunteer patient in a clinical setting. Examples: standardized patients are widely used to teach and assess communication and clinical skills; clinical teachers may encourage volunteer patients to teach and give feedback; students write up patients' stories.

3. Patient shares his/her experience with students within a faculty-directed curriculum. Examples: patients invited into the classroom to share experiences of chronic illness, disability etc.; community-based patient / family attachment programs; Senior mentor programs.

4. Patient-teacher(s) are involved in teaching or evaluating students. Examples: Teaching associates trained to teach and assess specific clinical skills (e.g., pelvic or breast exam); patients give feedback to students on communication skills.

5. Patient-teacher(s) as equal partners in student education, evaluation, and curriculum development. Examples: patient-educators involved in multiple program areas. Patient educators collaborate in educational decision-making (e.g., curriculum objectives, assessment criteria).

6. Patients involved at institutional level in addition to sustained involvement as patientteacher(s) in education, evaluation, and curriculum development. Examples: Patients given a formal position in the institution (e.g., Consumer Academic). Patients involved in institutional decision-making (e.g., student selection, reviewing funding applications).

\section{Appendix 2: Key findings from the community interviews and dialogue}

Involvement in the education of students

Health professionals need to be better at working in partnership

People from the community have a variety of expertise to share with health professionals

Patients and community members could be involved in many different educational activities

Students need to be prepared for a different kind of learning

Supporting community educators

Recognize and honour patient and community expertise

Learning activities that involve vulnerable citizens need to be based in the community 
Develop mechanisms to accommodate special needs and vulnerabilities of community educators

Provide appropriate training and support for community educators

Additional training and mentorship are needed for levels of involvement that involve decisionmaking

Engagement between community organizations and the university

Avoid 'academic projectitis' and invite on-going, mutually beneficial relationships with community organizations and their members that support their involvement in educating students

Develop staff liaisons based in community organizations to broker relationships between the university and community educators

Create a mechanism for the community to communicate with the university

A partnership with the university is beneficial to the community 